\title{
ANALISIS KELAYAKAN FINANSIAL USAHA SARI BUAH MATOA DI KECAMATAN SUKOREJO KABUPATEN PASURUAN
}

\author{
Fijri Dita Nuralamika ${ }^{1} *$, Rahayu Relawati ${ }^{2}$, Istis Baroh ${ }^{3)}$ \\ ${ }^{1)}$ Mahasiswa Program Studi Magister Agribisnis, Universitas Muhammadiyah Malang \\ 2,3) Dosen Program Studi Magister Agribisnis, Universitas Muhammadiyah Malang \\ E-mail : fijridita@gmail.com ${ }^{1) *}$, rahayurelawati@umm.ac.id ${ }^{2)}$, istis@umm.ac.id $^{3)}$
}

\begin{abstract}
ABSTRAK
Olahan produk buah matoa menjadi minuman dalam kemasan sari buah yang belum banyak dikenal oleh masyarakat secara luas masih terbilang usaha yang baru di Kecamatan Sukorejo Kabupaten Pasuruan sehingga kelayakan finansial usaha masih perlu dikaji. Tujuan penelitian ini untuk menganalisis kelayakan finansial dan sensitivitas sari buah matoa. Penelitian ini dilakukan di Kecamatan Sukorejo Kabupaten Pasuruan Jawa Timur. Metode analisis data yang digunakan adalah kelayakan finansial menggunakan kriteria investasi. Jenis data dalam penelitian adalah data primer yang diolah diperoleh langsung melalui wawancara dan observasi kepada produsen home industry sari buah matoa.Teknik pengambil responden dilakukan secara purposive di Kecamatan Sukorejo Kabupaten Pasuruan Jawa Timur. Hasil penelitian menunjukkan bahwa nilai NPV positif sebesar Rp.16.984.566, IRR sebesar 11.46\%, Gross B/C sebesar 1.05, Net B/C sebesar 1.36, Payback Period sebesar 5 bulan, dan hasil analisis sensitivitas menunjukkan kelayakam finansial terhadap kenaikan maupun penurunan sebesar $10 \%$ pada usaha sari buah matoa adalah komponen benefit menunjukkan sensitif terhadap kenaikan harga bahan baku buah matoa dengan nilai $13.34 \%$ sedangkan penurunan benefit sensitif terhadap penurunan kuantitas produksi dengan nilai $-5.9 \%$. Hasil penelitian dapat disimpulkan bahwa usaha sari buah matoa dikatakan layak dikembangkan dari hasil perhitungan kriteria finansial dan sensitivitas usaha, namun apabila terjadi penurunan sebesar $10 \%$ usaha mengalami kerugian maka pengusaha sari buah matoa agar dapat meningkatkan kuantitas produksi, memperhatikan harga jual produk, ketersediaan bahan baku, dan melakukan promosi penjualan untuk meningkatkan pendapatan usaha.
\end{abstract}

Kata kunci: Kelayakan Finanasial, Sensitivitas, Sari Buah, Matoa

\section{PENDAHULUAN}

Indonesia dikenal sebagai negara yang memiliki sumber daya alam berlimpah. Sektor pertanian adalah sektor yang mampu memberikan peranan strategis dalam perkembangan perekonomian di Indonesia, salah satunya perkembangan perekonomian melalui bidang agribisnis (Soekartawi, 1999; Syaifuddin, 2005; Darmansyah et al., 2014). 
Bidang agribisnis pertanian yang mencakup aktivitas subsistem hulu sampai hilir memberikan banyak manfaat untuk meningkatkan nilai tambah serta keunggulan suatu produk pertanian dalam mengelolah pengembangan prospek bisnis bagi pelaku usaha (Sumastuti, 2011; Andri et al., 2015; Hamidah et al., 2015).

Kegiatan agribisnis membutuhkan bahan baku untuk proses kegiatannya sehingga perkembangan usaha mempunyai potensi untuk dapat dikembangkan mengingat adanya ketersediaan pasokan bahan baku buah matoa yang dapat tumbuh di Kabupaten Pasuruan. Buah matoa (Pometia pinnata) merupakan buah lokal khas Papua yang tumbuh di wilayah Papua yang mempunyai cita rasa seperti campuran rasa rambutan, kelapa muda, kelengkeng, dan rasa buah durian (BPTP, 2016; Mentan, 2006). Selama ini buah matoa dikonsumsi secara segar dan belum banyak minuman olahan dalam kemasan seperti sari buah. Buah matoa sebagai bahan baku utama pembuatan sari buah ini banyak dibudidayakan oleh petani di daerah Pasuruan Jawa Timur (Pemkab Pasuruan, 2016), sehingga buah matoa memiliki potensi besar untuk dikembangkan menjadi suatu produk olahan.

Beberapa penelitian terdahulu telah melakukan pengembangan tentang buah matoa antara lain studi buah matoa melalui pengembangan booklet penyuluhan inovasi pengolahan dalam pembuatan nata de matoa pada petani di Kecamatan Sukorejo (Edy, Hastuti, \& Gofur, 2017); pemanfaatan buah matoa sebagai cita rasa dalam es krim (Nuryadi et al.,2019); pendampingan pemanfaatan buah matoa melalui pemberdayaan masyarakat dengan metode Participatory Rural Appraisal (PRA) desa Gunting Kecamatan Sukerjo Kabupaten Pasuruan (Aslikhah, 2019); uji teknologi dan nilai tambah buah matoa melalui pembuatan sirup matoa pada skala rumah tangga
(Leiwakabessy \& Paga, 2018). Penelitian terkait tentang kelayakan finansial ditemukan pada usaha sari buah apel di Koperasi Usaha Mandiri Lestari Makmur dengan analisis biaya produksi dan keuntungan usaha, kelayakan usaha R/C Ratio dan BEP (Hanani et al., 2012); kelayakan usaha sari buah belimbing di Kota Blitar dengan analisis NPV, IRR, Net B/C, Gross B/C, profitability (Ibrahim \& Bakhtiar, 2017); manajemen produksi dan kelayakan finansial agroindustri sirup markisa yaitu pendapatan, NPV, IRR, Net B/C, PP (Aulia et al., 2019); kelayakan usaha sari buah jeruk di UD.Margo Mulyo Malang yaitu BEP, IRR dan saluran pemasaran(Suliana \& Rusdiana, 2010); kelayakan finansial produk jus wortel nanas menghitung kelayakan finansial NPV, B/C, IRR, BEP, PBP (Sari, et al., 2019); kelayakan usaha pada produksi setup buah nipah skala Industri Kecil dan Menengah (IKM) yaitu perhitungan HPP, NPV,IRR,R/C ratio, BEP, PP (Dewi et al., 2019); analisis kelayakan usaha pada minuman berbasis whey dan sari buah topis selama periode 5 bulan menganalisis $\mathrm{R} / \mathrm{C}$ ratio dan payback period (Pradana et al., 2017). Diantara penelitian tersebut menganalisis studi kelayakan finansial usaha baik dengan preferensi strategi pemasaran, pengembangan manajemen produksi, BEP, Net B/C, Gross B/C, PP, NPV, dan IRR, namun penelitian secara khusus pada studi kelayakan finansial dan analisis sensitivitas usaha pada olahan minuman sari buah matoa belum diteliti. Penelitian ini menyajikan analisis kelayakan finansial yaitu NPV, IRR, Net B/C, Gross B/C dan sensitivitas dari usaha olahan buah matoa asli Papua yang tumbuh subur di Kabupaten Pasuruan menjadi minuman kemasan sari buah.

Pengolahan buah segar matoa menjadi produk olahan yang digemari konsumen sebagai minuman buah karena praktis dan lebih awet dibandingkan buah matoa segar, 
serta konsumen bisa menikmatinya dengan mudah dan ringan tanpa perlu datang ke Papua untuk menikmati buah matoa, sehingga pengolahan industri usaha olahan buah matoa saat ini perlu untuk dikembangkan dan dikenal oleh masyarakat secara luas. Tujuan dari penelitian ini adalah menganalisis kelayakan finansial dan sensitivitas usaha produk olahan sari buah matoa untuk membantu pengusaha dalam menjalankan bisnisnya agar dapat mengurangi resiko yang mungkin terjadi di masa depan.

\section{METODE PENELITIAN}

Penelitian ini dilakukan di Kecamatan Sukorejo Kabupaten Pasuruan Jawa Timur. Pemilihan lokasi penelitian dilakukan secara purposive sampling berdasarkan ketersediaan pelaku home industry yang bergerak dalam bidang produksi dan pemasaran buah matoa olahan. Penelitian dilaksanakan pada bulan Desember 2020.

Teknik pengambilan sampel dalam penelitian ini dilakukan secara purposive pada pelaku home industry yaitu satu produsen sari buah matoa. Jenis data yang digunakan dalam penelitian ini adalah data primer yang diperoleh langsung dari responden pelaku usaha olahan matoa dan data sekunder sebagai literatur dalam mendukung penelitian ini. Teknik pengumpulan data primer dalam penelitian dilakukan dengan wawancara terstuktur dan mendalam kepada pengusaha olahan buah matoa.

Analisis dalam penelitian ini menggunakan analisis finansial yaitu analisis kelayakan yang dilihat dari sisi pemilik usaha. Adapun kriteria dalam melihat kelayakan suatu proyek antara lain Net Present Value (NPV), Internal Rate of Return (IRR), Payback Period (PP), Net Benefit Cost Ratio (B/C Ratio), Gross B/C Ratio ( Pudjosumarto, 2002; Clive et al., 2007). Analisis sensitivitas untuk melihat pengaruh yang mungkin terjadi pada usaha akibat suatu keadaan yang berubah dalam dasar perhitungan biaya (Gittinger, 2010; Gasnawati et al., 2021). Pengolahan data dalam penelitian ini dilakukan dengan tabulasi dan dianalisis dengan merujuk pada aspek perhitungan analisis kelayakan finansial usaha sari buah matoa.

\section{HASIL DAN PEMBAHASAN}

Kriteria kelyakan usaha pada sari buah matoa yang digunakan dalam analisis finansial yaitu NPV, IRR, Gross B/C, Net B/C, Payback Period. Analisis yang digunakan pada usaha sari buah matoa yaitu satu periode 12 bulan yang didasarkan pada investasi usaha yang telah dilakukan home industry sari buah matoa untuk mendukung peningkatan pengolahan produk pertanian di daerah setempat. Perhitungan analisis finansial menggunakan discount factor pada tingkat suku bunga kredit usaha mikro (KUR) sebesar $6 \%$ per tahun 2020. Biaya yang dikeluarkan dalam usaha pengolahan sari buah matoa adalah biaya investasi dan biaya operational dapat di lihat pada tabel 1.

Tabel 1. Biaya Investasi dan Operational Sari Buah Matoa selama 12 bulan (dalam ribuan)

\begin{tabular}{cr}
\hline Biaya & Nilai (Rp) \\
\hline Biaya Investasi & 47.355 \\
Biaya Operational & 217.266 \\
\hline
\end{tabular}

Sumber : Data Primer Diolah (2021)

Tabel 1 menunjukkan hasil pengolahan data diperoleh biaya investasi yang digunakan selama menjalankan usaha untuk menunjang kegiatan produksi sari buah matoa pada usaha home industry adalah sebesar Rp. 47.355.000 yang terdiri dari total investasi awal usaha dalam pembelian alat produksi, sewa bangunan usaha, perizinan, kendaraan, laptop, etalase, dan mesin sealer penyegel. Pada nilai invetasi menggunakan nilai penyusutan 
dikarenakan pada umur ekonomis usaha belum habis, sedangkan modal kerja usaha berasal dari modal pribadi $40 \%$ dan pinjaman bank $60 \%$ dengan periode pinjaman selama 2 tahun. Total biaya operational selama 12 bulan menjalankan produksi sari buah matoa sebesar Rp. 217.266.000 yang terdiri dari biaya pembelian bahan baku usaha, bahan pengemasan, bahan pembantu, gaji tenaga kerja, biaya pemeliharaan, listrik dan pulsa, biaya pemasaran. Pengeluaran terbesar dalam biaya operational adalah pembelian bahan baku yang mencapai Rp.109.260.000 atau $50.29 \%$ untuk menjaga kualitas produk yang dihasilkan. Usaha sari buah matoa mampu memproduksi produk dalam satu tahun sebanyak 17.000 cup atau botol sari buah tergantung dari permintaan pasar, dan dalam satu kali produksi mampu menghasilkan sebanyak 1000 sampai 3000 cup atau botol sari buah matoa sekali produksi. Penerimaan dari hasil penjualan sari buah matoa pada kemasan ukuran cup $220 \mathrm{ml}$ dan botol $330 \mathrm{ml}$ dengan total penerimaan sebesar Rp.374.000.000 per tahun.

\section{Kelayakan Finansial Usaha}

Kelayakan usaha sari buah matoa terdapat cashflow yang terdiri dari aliran kas masuk meliputi pendapatan pada hasil penjualan dan aliran kas keluar meliputi biaya investasi, operational, pajak, dan pembayaran angsuran pinjaman kredit. Cashflow tersebut digunakan dalam perhitungan menjalankan usaha dan untuk mengetahui kelayakan finansial usaha sari buah matoa yaitu NPV,IRR, Gross B/C, Net B/C, dan PP. Hasil kelayakan dapat dilihat dalam tabel 2 .

Tabel 2. Analisis kelayakan finansial sari buah matoa di Kecamatan Sukorejo Kabupaten Pasuruan.

\begin{tabular}{clc}
\hline No & \multicolumn{1}{c}{ Uraian } & Nilai \\
\hline 1 & $\begin{array}{l}\text { Net Present Value } \\
\text { (NPV) }\end{array}$ & Rp. 16.984.566
\end{tabular}

$\begin{array}{lll}2 & \text { Internal Rate of } & 11.46 \% \\ & \text { Return (IRR) } & 1.05 \\ 3 & \text { Gross B/C } & 1.36 \\ 4 & \text { Net B/C } & \text { 5 bulan } \\ 5 & \text { Payback Period (PP) }\end{array}$

Sumber : Data Primer Diolah (2021)

Net Present Value (NPV) merupakan perhitungan nilai bersih pada waktu sekarang dengan menggunakan tingkat discount factor yang berlaku dan usaha dapat dikatakan layak dijalankan apabila nilai NPV $>0$ (Clive et al., 2007; Pudjosumarto, 2002). Dari hasil perhitungan NPV diperoleh hasil bernilai positif $>0$ yaitu sebesar Rp. 16.984.566 dari DF sebesar 6\%. Nilai yang diperoleh menunjukkan bahwa investasi pada usaha sari buah matoa dalam periode 12 bulan diperoleh manfaat nilai bersih yang dinilai saat ini, artinya usaha tersebut layak untuk dikembangkan.

Internal Rate of Return (IRR) merupakan perhitungan tingkat kemampuan suatu proyek dalam menghasilkan return dengan nilai lebih besar dibandingkan dengan suku bunga yang ditetapkan (Clive et al., 2007). IRR dari usaha sari buah matoa diperoleh nilai sebesar $11.46 \%$ artinya usaha tersebut mampu memberikan tingkat pengembalian dana invetasi sebesar $11.46 \%$ per tahun dan nilai IRR tersebut lebih besar jika dibandingkan dengan suku bunga yang ditetapkan yaitu $6 \%$.

Pada hasil perhitungan usaha sari buah matoa diperoleh nilai Gross B/C sebesar 1.05 yang artinya nilai tersebut $>1$ berarti usaha sari buah matoa layak untuk diteruskan. Perhitungan Net $B / C$ menghasilkan nilai sebesar 1.36 artinya nilai tersebut $>1$ berarti setiap pengeluaran Rp. 1.00 akan mendapat benefit sebesar Rp. 1.36. Nilai net benefit positif berbanding dengan net benefit negatif pada sari buah matoa menghasilkan nilai 37.4. Menurut (Bakhtiar et al., 2018) perhitungan Net Benefit Cost Rasio yaitu Net B positif 
berbanding dengan Net negatif, yaitu pada usaha agroindustri tahu pada DF $12 \%$ menghasilkan nilai 19.15 dan nilai $\mathrm{Net} \mathrm{B} / \mathrm{C}>1$ yang artinya setiap pengeluaran Rp.10.000.000 mendapatkan benefit Rp.191.540.000 dan usaha tersebut dikatakan layak dijalankan. Hal ini sama dengan hasil penelitian (Ibrahim \& Bakhtiar, 2017) nilai Gross B/C sebesar 1.3 dan Net B/C sebesar 4.09 pada sari belimbing menunjukkan nilai lebih dari satu artinya usaha layak untuk dijalankan. Nilai Gross B/C kelayakan usaha tersebut lebih kecil $0.25 \%$ dan Net B/C lebih kecil $2.73 \%$ dari sari buah matoa. Dengan demikian usaha sari buah matoa dilihat dari nilai Gross B/C dan Net B/C usaha lebih dari satu sehingga usaha layak untuk dikembangkan. Payback Period pada usaha sari buah matoa dicapai pada usaha berjalan bulan ke 5 dari proyek usaha sari buah matoa selama 12 bulan.

\section{Analisis Sensitivitas}

Analisis sensitivitas digunakan untuk melihat pengaruh yang terjadi karena suatu perubahan ketidakpastian di masa depan (Gasnawati et al., 2021). Analisis sensitivitas usaha sari buah matoa dilakukan untuk melihat suatu usaha masih layak dikembangkan apabila komponen usaha mengalami perubahan sehingga dapat mengurangi risiko kerugian atau usaha dapat diantisipasi sebelumnya dengan mengambil langkah tepat dalam pengelolaan usaha. Pada penelitian analisa usaha sari buah matoa dilakukan pada dua skenario analisis sensitivitas pada tingkat komponen benefit atau penerimaan usaha yaitu :

I) Jika terjadi kenaikan benefit $10 \%$

II) Jika terjadi penurunan benefit $10 \%$

Tabel 3. Analisis sensitivitas usaha sari buah matoa di Kecamatan Sukorejo Kabupaten Pasuruan.

\begin{tabular}{lll}
\hline $\begin{array}{c}\text { Kriteria } \\
\text { Usaha }\end{array}$ & \multicolumn{1}{c}{$\begin{array}{c}\text { Benefit } \\
\text { naik 10\% }\end{array}$} & \multicolumn{1}{c}{$\begin{array}{c}\text { Benefit } \\
\text { turun 10\% }\end{array}$} \\
\hline NPV (Rp) & Rp.53.318.639 & Rp.(19.349.506) \\
Gross B/C & 1.15 & 0.94 \\
Net B/C & 2.13 & 0.59 \\
IRR & $16.88 \%$ & $-22.36 \%$ \\
Tingkat & $13.34 \%$ & $-5.9 \%$ \\
Kepekaan & \\
\hline
\end{tabular}

Sumber : Data Primer Diolah (2021)

Pada parameter penurunan dan peningkatan benefit sebesar 10\% dari harga semula dan sementara biaya yang lain diasumsikan tetap maka terjadi perubahan nilai masing-masing NPV, Gross B/C, Net $\mathrm{B} / \mathrm{C}$, dan IRR. Hasil perhitungan tabel 3 menunjukkan apabila benefit naik sebesar $10 \%$ maka dikatakan usaha sari buah matoa layak dikembangkan dan masih menguntungkan walaupun terjadi kenaikan maupun penurunan sampai pada tingkat suku bunga sebesar $6 \%$, sedangkan apabila terjadi penurunan biaya benefit sebesar $10 \%$ maka usaha sari buah matoa dikatakan mengalami kerugian.

Pada analisis kriteria investasi yang memberikan penilaian layak untuk keberlanjutan usaha sari buah matoa, artinya apabila terjadi suatu perubahan keuangan usaha dan kondisi ekonomi yaitu penerimaan atau benefit meningkat $10 \%$ atau menurun $10 \%$ maka pada kondisi ini usaha sensitif terhadap perubahan. Kenaikan benefit usaha sebesar $10 \%$ pengolahan sari buah matoa sensitif terhadap kenaikan harga bahan baku buah matoa dengan nilai $13.34 \%$, sedangkan apabila penurunan benefit usaha sebesar $10 \%$ maka usaha sari buah matoa selain mengalami kerugian dan sensitif terhadap penurunan kuantitas produksi sari buah dengan nilai $5.9 \%$.

Hal ini berbeda dengan penelitian (Zain \& Ramadayanti, 2019) pada produk minuman 
cokelat menggunakan cocoa butter sustitute yang menyatakan bahwa analisa sensitivitas pada kriteria komponen benefit menunjukkan usaha layak dijalankan dan sensitivitas pada tingkat kenaikan biaya bahan baku dan bahan pembantu sebesar $20 \%$ tidak sensitif atau tidak berpengaruh secara siginifikan pada kelayakan bisnis minuman cokelat, sedangkan pada sensitivitas harga jual yang turun $20 \%$ usaha dikatakan layak walaupun terjadi penurunan harga jual produk. Dengan demikian usaha sari buah matoa pada analisis sensitivitas layak atau menguntungkan apabila terjadi peningkatan benefit dalam usaha dan apabila terjadi penurunan maka akan mengalami kerugian usaha, maka pengusaha diharapkan dapat menjaga ketersediaan pasokan bahan baku dalam setiap produksinya, kualitas dan kuantitas produk, peningkatan promosi dan memperhatikan harga jual sari buah matoa.

\section{KESIMPULAN}

Berdasarkan hasil analisis kelayakan finansial dan sensitivitas pada sari buah matoa di Kecamatan Sukorejo Kabupaten Pasuruan bahwa usaha tersebut layak untuk dilaksanakan dengan nilai NPV positif sebesar Rp. 16.984.566, nilai IRR lebih besar dari tingkat suku bunga $6 \%$ yaitu sebesar $11.46 \%$, Gross B/C sebesar 1.05, Net B/C sebesar 1.36, dan Payback Period sebesar 5 bulan. Analisis sensitivitas usaha tersebut sensitif terhadap terjadinya peningkatan dan penurunan pada komponen benefit. Dengan demikian usaha sari buah matoa di Kecamatan Sukerejo Kabupaten Pasuruan masih tetap layak untuk dijalankan.

Dari hasil analisis perhitungan maka diharapkan kepada pengusaha pengolahan sari buah matoa dapat menjaga jumlah produksi usaha minuman sari buah matoa dengan ketersedian bahan baku utama buah matoa, melakukan promosi serta tetap mengutamakan kualitas produk dan menjaga nilai harga jual produk, sehingga produk dapat diterima konsumen dan pendapatan pelaku usaha meningkat, serta diperlukan pembinaan pendampingan secara berkala kepada pelaku usaha mengingat potensi usaha pengolahan sari buah matoa berpotensi untuk dikembangkan lebih lanjut.

\section{DAFTAR PUSTAKA}

Andri, K. B., Willem, J. F., \& Tumbuan, A. (2015). Potensi Pengembangan Agribisnis Bunga Anggrek Di Kota Batu Jawa Timur. Jurnal LPPM Bidang EkoSosBudKum, 2(1), 19-30.

Aslikhah, A. (2019). Sinergitas Program Matoanisasi pada Masyarakat Desa Gunting Melalui Participatory Rural Appraisal (PRA). Jurnal Soeropati: Jurnal Pengabdian Kepada Masyarakat, 2(1), 61-70.

Aulia, A., Rasyid, R., \& Nurliani, N. (2019). Analisis Manajemen Produksi Dan Kelayakan Finansial Usaha Agroindustri Sirup Markisa. Jurnal Wiratani, 2(1), 2438.

BPTP Papua Barat. (2016). Mengenal Buah Matoa Lebih Dekat. http://papuabarat.litbang.pertanian.go.id/i ndex.php/publikasi/artike1/228-mengenalbuah-matoa-lebih-dekat Diakses 9 Januari 2021

Bakhtiar, A., Ibrahim, J. T., \& Relawati, R. (2018). Financial Feasibility Analysis Of Tofu Agroindustry "RDS" (Case Studi in "RDS" Tofu Processing Agro-Industry in Sub District of Singosari, Distric of Malang). Jurnal Agribest, 02(02), 178-174.

Clive, G., Simanjuntak, P., Sabur, L. K., Maspaitella, P. F. L., \& Varley, R. C. G. (2007). Pengantar Evaluasi Proyek Edisi Kedua. Jakarta: PT. Gramedia Pustaka 
Utama.

Darmansyah, A., Rochana, S. H., Sutardi, A., \& Zuraida, U. (2014). The New Growth Centres and Strategy for Building and Accelerating Agribusiness Development in Cirebon Regency, Indonesia. Procedia - Social and Behavioral Sciences, 115, 296-304.

https://doi.org/10.1016/j.sbspro.2014.02. 437

Dewi, I. A., Effendi, U., Wijana, S., \& Sari, N. D. (2019). Analisis Kelayakan Finansial Produksi Setup Buah Nipah Pada Skala Industri Kecil Menengah (IKM). Jurnal Teknologi Pertanian, 20(1), 25-32. https://doi.org/10.21776/ub.jtp.2019.020. 01.3

Edy, M. A., Hastuti, U. S., \& Gofur, A. (2017). Pengembangan Booklet Penyuluhan "Nata de Matoa" Bagi Para Petani Buah Matoa. Jurnal Pendidikan: Teori, Penelitian Dan Pengembangan, 2(7), 971-973.

Gasnawati, R. A., Abdi, A., \& Hamzah, A. (2021). Sensitivity Analysis of Decorative Plant Business in Kendari City (Case Study on Dahlia Ornamental Plant Business). International Journal of Agricultural Social Economics and Rural Development (Ijaserd), 1(1), 13-16. https://doi.org/10.37149/ijaserd.v1i1.141 59

Gittinger, J. P. (2010). Analisa Ekonomi Proyek Pertanian (Kedua). Jakarta: UI PRESS-Johns Hopkins.

Hamidah, M., Yusra, A. H. A., \& Sudrajat, J. (2015). Analisis Nilai Tambah Agroindustri Kripik Ubi Di Kota Pontianak. Journal Social Economic of Agriculture, 4(2), 60-73.
Hanani, N., Asmara, R., \& Hanafi, A. A. (2012). Analysis of Business And Feasibility In The Drink Of Agroindustry Extract Apple. Journal Agrise, XII(1), $13-24$.

Ibrahim, J. T., \& Bakhtiar, A. (2017). Analisis Kelayakan Usaha Sari Buah Belimbing Di Kota Blitar. JSEP (Journal of Social and Agricultural Economics), 10(3), 5357.https://doi.org/10.19184/jsep.v10i3.55 38

Kementerian Pertanian. (2006). Keputusan Menteri Pertanian Tentang Pelepasan Matoa Papua Sebagai Varietas Unggul. http://perundangan.pertanian.go.id/admin /k_mentan/SK-160-06.pdf Diakses 9 Januari 2021

Leiwakabessy, I. M., \& Paga, O. B. (2018). Uji Teknologi Pembuatan Sirup Matoa (Pometia pinnata) Skala Rumah Tangga. Median : Jurnal Ilmu-Ilmu Eksakta, X, 18.

Nuryadi, A. M., Silaban, D. P., Manurung, D. P., \& Apriani, S. W. (2019). Pemanfaatan Buah Matoa Sebagai Cita Rasa Es Krim Yang Baru. Jurnal Penelitian Teknologi Industri, 11(2), 55-62.

Pemkab Pasuruan. 2016. Sukorejo Siap Menjadi City of Matoa. https://www.pasuruankab.go.id/berita2419-sukorejo-siap-menjadi-city-ofmatoa.html Diakses 9 Januari 2021

Pudjosumarto, M. (2002). Evaluasi Proyek (Kedua). Yogyakarta: Liberty.

Pradana, F. R., Anwar, C., Fridayani, N., Aziz, H. A., \& Assyfa, A. N. (2017). Inovasi Minuman Sehat Berbasis Whey Dan Sari Buah Tropis. AJIE-Asian Journal of 
Innovation and Entrepreneurship, 02(03), 2477-3824.

Sari, M., Nurmaydha, A., \& Rohmah, D. U. M. (2019). Financial Feasibility Analysis of Pineapple Carrot Juice Business. Journal of Physics: Conference Series, 1381(1). https://doi.org/10.1088/17426596/1381/1/012034

Suliana, G., \& Rusdiana, E. (2010). Analisis Kelayakan Usaha Dan Pemasaran Sari Buah Jeruk Manis Di UD Margo Mulyo Dau Malang. Jurnal Buana Sains, 10(1), 41-46.

Sumastuti, E. (2011). Prospek Pengembangan Agribisnis Dalam Mewujudkan Ketahanan Pangan. Jurnal Ekonomi Dan Kebijakan, 4(2), 154-161. https://doi.org/10.15294/jejak.v4i2.4650

Syaifuddin. (2005). Pengembangan Agribisnis Sebagai Penggerak Utama Perekonomian Nasional. Jurnal Penelitian Bidang Ilmu Pertanian, 3(3), 51-58.

Soekartawi. 1999. Agribisnis Teori dan Aplikasi. PT. Raja Grafindo Persada. Jakarta.

Zain, E. R., \& Ramadayanti, M. (2019). Financial Analysis Of Production Fee From Chocholate Drink Using Cocoa Butter Substitute From Palm Oil. Journal Agroindustri Halal, 5(1), 085-093. 